IP Periodica Polytechnica Mechanical Engineering

61(1), pp. 44-54, 2017

DOI: $10.3311 /$ PPme. 9283

Creative Commons Attribution (i)

RESEARCH ARTICLE

\section{Two-Dimensional Finite Element Analysis of Turning Processes}

\author{
Benjámin Borsos ${ }^{1}$, András Csörgö ${ }^{1}$, Anna Hidas ${ }^{1}$, Bálint Kotnyek ${ }^{1 *}$, \\ Antal Szabó ${ }^{\text {, Attila Kossa }}{ }^{1}$, Gábor Stépán ${ }^{1}$
}

Received 06 April 2016; accepted after revision 31 October 2016

\begin{abstract}
Despite crucial efforts invested into computational methods, explicit dynamics simulation of cutting operations may still be unacceptably expensive. Therefore, in many cases a twodimensional model is considered. Here an overview of the possibilities of two-dimensional simulations is given. For this, simulation and measurement of a straight turning process on AISI 1045 steel is presented. In the numerical analysis, material behavior and its failure was described by Johnson-Cook law, considering damage evolution. Coupled thermo-mechanical model with mass-scaling and adaptive remeshing was built. The numerically obtained cutting force was compared to the measured data. It was found that the forces obtained with simulation and the measured ones show good agreement. Sensitivity analyses were performed to examine the influence of specific parameters on the reaction force. The effect of these parameters is also shown.
\end{abstract}

\section{Keywords}

Finite element modelling, Cutting forces, Turning, 2D simulation

${ }^{1}$ Department of Applied Mechanics,

Faculty of Mechanical Engineering,

Budapest University of Technology and Economics,

H-1111 Budapest, Müegyetem rkp. 5., Hungary

*Corresponding author, e-mail: kotnyek.balint@gmail.com

\section{Introduction}

Cutting is one of the most important material removal process. In case of mass production even small enhancement of a machining process can cause significant cost reduction and quality improvement for the product. Deeper understanding of the relation between machining parameters (cutting speed, feed rate, depth of cut, etc.) and output variables (cutting forces, temperature field, surface roughness, chip morphology, etc.) could be a key to such improvement.

In the last few decades, substantial research effort has been invested into the development of computational methods and their implementations. Thus the identification of physical variables in simulations of machining processes could be performed efficiently.

Despite the efforts to reduce the cost of computational speed, explicit dynamics simulation of cutting operations may still be unacceptably expensive. Consequently, the usage of 2D model could be considered.

The main objective of the present paper is to give an overview of the possibilities of two-dimensional simulations of orthogonal cutting based on the comparison of the results obtained from simulations and previously performed measurements.

First an overview is given about the recent works on simulation approaches of machining processes. In most cases, finite element analysis software ABAQUS/Explicit was used, and two-dimensional model was applied.

Ducobu et al. [1] introduced three finite element models to test three theories applicable to model Ti6Al4V chip formation during orthogonal cutting. The reference experimental data was taken from Sun et al. [2]. In a different paper Ducobu et al. [3] examined the effect of adaptive mass scaling in finite element analysis of Ti6Al4V orthogonal cutting. Hokka et al. [4] introduced modelling, simulation and measurement of highspeed machining of Ti-6246 and Alloy 625 Superalloys. Ljustina et al. [5] summarized the know-how about continuum damagemodelsandmesh dependenceinFiniteElementAnalyses. Menezes et al. [6] studied the influence of rake angle and friction in an aluminium workpiece using FEA software LS-DYNA. 
Parle et al. [7] investigated modelling of microcrack formation in orthogonal cutting of AISI 1215 steel. Pres et al. [8] presented simulation, measurement and their comparison with respect to cutting forces and geometrical features of the chip. The material used was C45E. Wang et al. [9] investigated the serrated frequency and cutting force for Ti6Al4V. They compared their simulation results to experimental data, and concluded that the agreement was good between them. Xi et al. [10] presented a rather different approach, namely the smoothed particle hydrodynamics (SPH) Lagrangian method for 2D and 3D models in LS-DYNA. Vasiri et al. [11] showed a set of constants for the Johnson-Cook damage model calibrated for the AISI 1045 steel material. They managed to predict the resistance to cutting force well.

In the next section, the reference measurement is introduced. Section 3 details the finite element model. Explanation is given for two-dimensional modelling of three-dimensional cutting process in the particular case of the configuration introduced in Section 2. The constitutive model and damage model are explicated as well. Sensitivity analyses are carried out for mesh density, rake angle, contact, mass scaling methodology, ALE remeshing parameters.

In Section 4, the results of experiment and simulation are evaluated and compared. In Section 5, conclusion and further goals are summarized.

\section{Turning experiment}

The cutting tests were performed on a universal lathe machine (type: EU-630x300). A Kistler 9263A cutting force dynamometer was used to measure the cutting forces. Material of the selected insert was TN 123 (ISO P30C) and it was coated by titanium carbid (TiC). The insert was designated as CNMG 120408KM. The geometric details of the insert are summarized in Table 1.

Table 1 Details of the insert

\begin{tabular}{lll}
\hline $\begin{array}{l}\text { Insert shape } \\
\text { Relief angle }\end{array}$ & $\mathrm{C}$ & $\begin{array}{l}\text { Diamond (opening angle: } 80^{\circ} \text { ) } \\
0^{\circ}\end{array}$ \\
$\begin{array}{lll}\text { Tolerance } \\
\text { M }\end{array}$ & $\begin{array}{l}\text { Inscribed circle: } 0.15 \pm 0.05 \\
\text { Thickness: } 0.13 \mathrm{~mm}\end{array}$ \\
Cross section type & $\mathrm{G}$ & - \\
Cutting edge length & 12 & $12.7 \mathrm{~mm}$ \\
Height of cutting edge & 04 & $4.76 \mathrm{~mm}$ \\
Nose radius & 0.8 & $0.8 \mathrm{~mm}$ \\
Chip breaker & $\mathrm{KM}$ & - \\
\hline
\end{tabular}

This type of insert was equipped with chip breaker to subserve chip segmentation. The tool holder was PCLNR 2525 M12. The summary of the experimental setup is listed in Table 2.

AISI 1045 normalized carbon steel (C45) cylindrical workpiece was used with an external diameter of $160 \mathrm{~mm}$. The experimental setup is shown in Fig. 1.
Table 2 Summary of the experimental setup

\begin{tabular}{ll}
\hline Machine Tool & EU-630x300 \\
Workpiece material & AISI 1045 \\
Workpiece size & Cylinder with the diameter of $160 \mathrm{~mm}$ \\
Cutting Insert & CNMG 120408KM \\
Tool holder & PCLNR 2525 M12 \\
Spindle speed & $100,200,400 \mathrm{~min}^{-1}$ \\
Feed rate & $0.09,0.18,0.355 \mathrm{~mm}^{-12}$ \\
Depth of cut & $0.5,1,2 \mathrm{~mm}$ \\
Environment & Room temperature, dry conditions \\
\hline
\end{tabular}

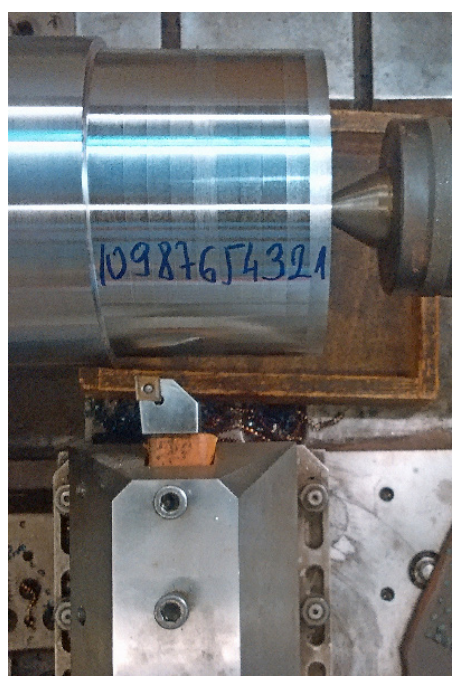

Fig. 1 Experimental setup

The cutting measurements were executed at three different cutting speeds, feed rate and cutting depth. In total 27 tests were performed.

Details of the test settings and the measured force values are summarized in Table 3. As a result of this measurement, the dependency of the acting force was evaluated with respect to the input parameters and settings of the tests (spindle speed, feed rate, cutting depth).

The measured data of test \#3 (Fig. 2) and \#11 (Fig. 3) are presented. Only the steady-state force signals were considered.

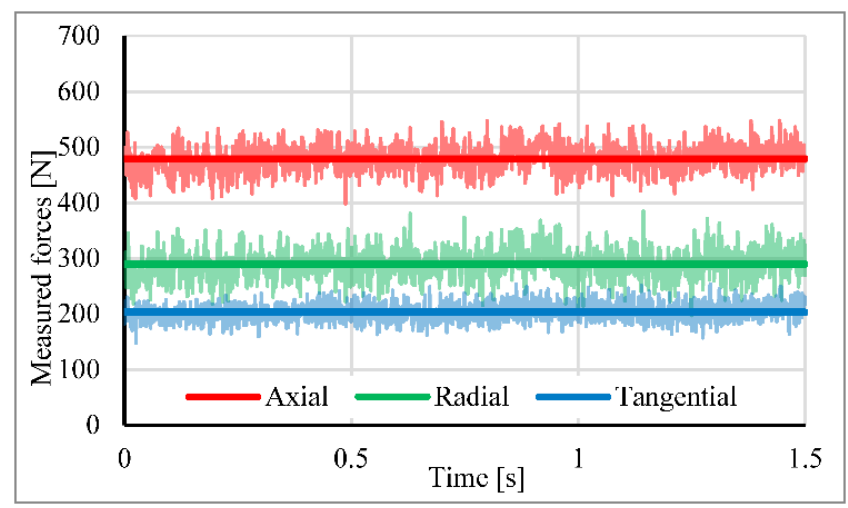

Fig. 2 Measured axial, radial and tangential force components at Measurement \#3 
Table 3 Results of the measurements

\begin{tabular}{|c|c|c|c|c|c|c|}
\hline \# & $\begin{array}{l}\mathrm{n} \\
\left(\min ^{-1}\right)\end{array}$ & $\begin{array}{l}\mathrm{f} \\
(\mathrm{mm})\end{array}$ & $\begin{array}{l}\mathrm{a} \\
(\mathrm{mm})\end{array}$ & $\begin{array}{l}\mathrm{F}_{\mathrm{x}} \\
{[\mathrm{N}]}\end{array}$ & $\begin{array}{l}\mathrm{F}_{\mathrm{r}} \\
{[\mathrm{N}]}\end{array}$ & $\begin{array}{l}\mathrm{F}_{\mathrm{t}} \\
{[\mathrm{N}]}\end{array}$ \\
\hline 1 & 100 & 0.09 & 0.5 & 139.2 & 77.8 & 69.6 \\
\hline 2 & 100 & 0.18 & 0.5 & 274.4 & 160.0 & 142.9 \\
\hline 3 & 100 & 0.355 & 0.5 & 479.0 & 289.7 & 203.2 \\
\hline 4 & 200 & 0.09 & 0.5 & 164.5 & 107.6 & 115.6 \\
\hline 5 & 200 & 0.18 & 0.5 & 267.3 & 161.9 & 153.1 \\
\hline 6 & 200 & 0.355 & 0.5 & 470.2 & 284.6 & 204.6 \\
\hline 7 & 400 & 0.09 & 0.5 & 151.6 & 90.4 & 106.4 \\
\hline 8 & 400 & 0.18 & 0.5 & 265.9 & 148.7 & 147.2 \\
\hline 9 & 400 & 0.355 & 0.5 & 432.2 & 231.0 & 171.0 \\
\hline 10 & 100 & 0.09 & 1 & 339.8 & 135.8 & 259.8 \\
\hline 11 & 100 & 0.18 & 1 & 559.1 & 232.7 & 388.1 \\
\hline 12 & 100 & 0.355 & 1 & 920.7 & 431.6 & 543.4 \\
\hline 13 & 200 & 0.09 & 1 & 313.1 & 144.8 & 248.0 \\
\hline 14 & 200 & 0.18 & 1 & 503.9 & 217.6 & 336.4 \\
\hline 15 & 200 & 0.355 & 1 & 855.3 & 399.3 & 468.9 \\
\hline 16 & 400 & 0.09 & 1 & 278.8 & 129.7 & 218.9 \\
\hline 17 & 400 & 0.18 & 1 & 451.0 & 186.0 & 280.7 \\
\hline 18 & 400 & 0.355 & 1 & 788.6 & 321.9 & 382.1 \\
\hline 19 & 100 & 0.09 & 2 & 562.7 & 157.4 & 389.1 \\
\hline 20 & 100 & 0.18 & 2 & 917.3 & 248.4 & 597.8 \\
\hline 21 & 100 & 0.355 & 2 & 1842.8 & 571.0 & 1248.7 \\
\hline 22 & 200 & 0.09 & 2 & 562.6 & 154.6 & 461.4 \\
\hline 23 & 200 & 0.18 & 2 & 900.3 & 246.2 & 621.0 \\
\hline 24 & 200 & 0.355 & 2 & 1602.1 & 456.1 & 939.3 \\
\hline 25 & 400 & 0.09 & 2 & 510.1 & 141.5 & 459.2 \\
\hline 26 & 400 & 0.18 & 2 & 836.3 & 231.7 & 588.2 \\
\hline 27 & 400 & 0.355 & 2 & 1417.4 & 363.6 & 747.1 \\
\hline
\end{tabular}

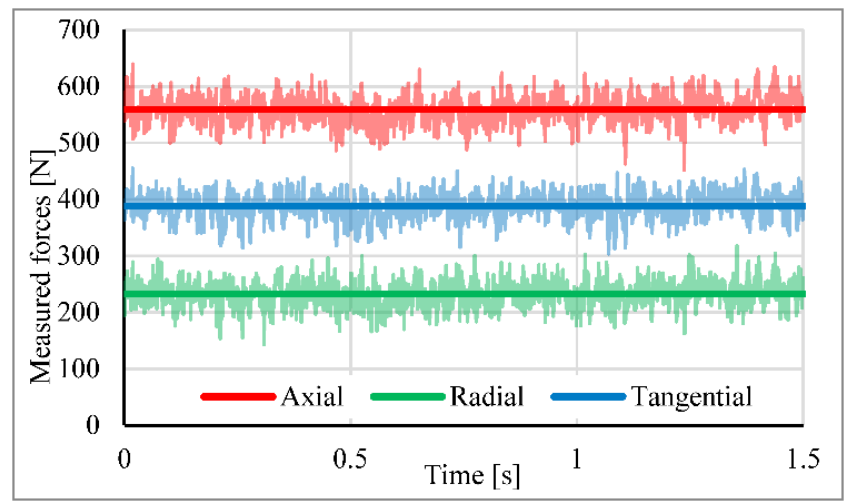

Fig. 3 Measured axial, radial and tangential force components at Measurement \#11

The averaged force values were calculated and during the evaluation of the FE simulation these results are used as reference. Chip shapes are shown in Fig. 4.

\section{FE - model}

\subsection{Overview}

A two dimensional ALE FE model was built using ABAQUS/ Explicit version 6.14 to simulate the previously performed turning process of stainless steel AISI 1045. Coupled thermomechanical analysis was used to include thermal effects. As an output of the simulation, the resultant forces of tool nodes were captured.

\subsection{Geometry and boundary conditions}

To simulate a three dimensional process in two dimensions it is essential to define a proper projection of the $3 \mathrm{D}$ case to $2 \mathrm{D}$. The turning process is simplified by considering only a small segment from the workpiece. Since the depth of cut, feed rate and the simulated workpiece arc is negligibly small compared to the radius of the workpiece, the segment is considered to be straight. 


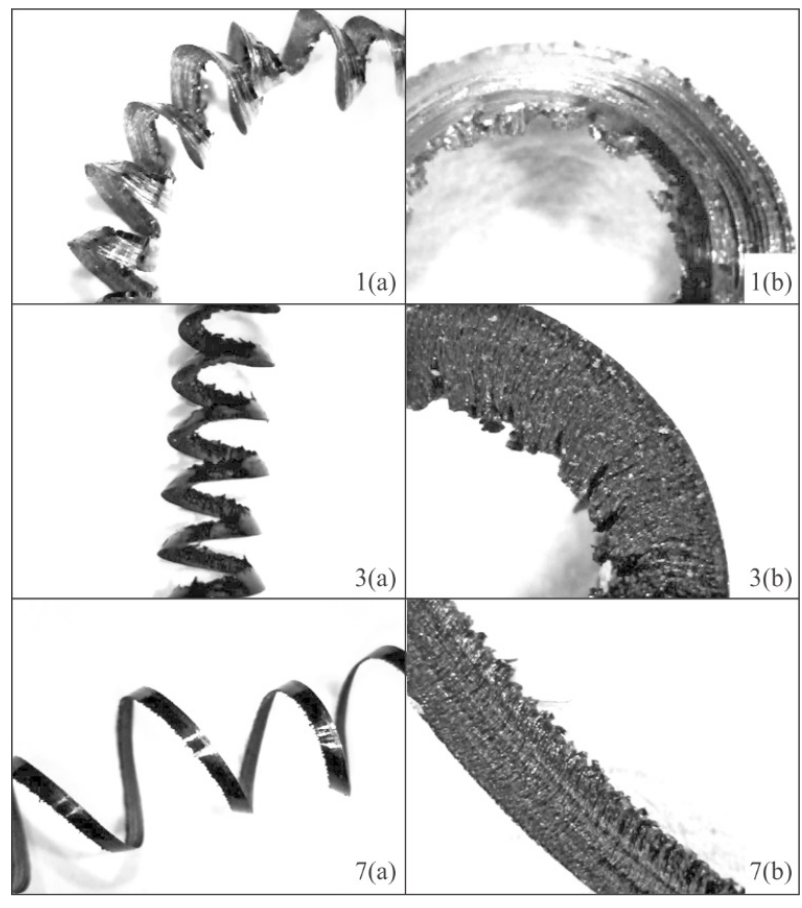

Fig. 4 Images of the resulted chips. Distant (a) and close-up (b) images

In this particular machining process, two edges of the tool are involved in cutting, while in the 2D simulation, only one cutting edge could be taken into account. Therefore, before the simulations, it also has to be decided which cutting edge is considered as dominant, and which one is neglected. In this study, the simulated cutting edge is indicated in Fig. 5 as cutting edge 1 . According to this projection the distance between the tooltip and the top edge of the workpiece presented in Fig. 7 corresponds to the feed rate from the measurement data, not to the depth of cut. The resultant reaction forces correspond to unit depth of cut, with a dimension of $\mathrm{N} / \mathrm{mm}$.

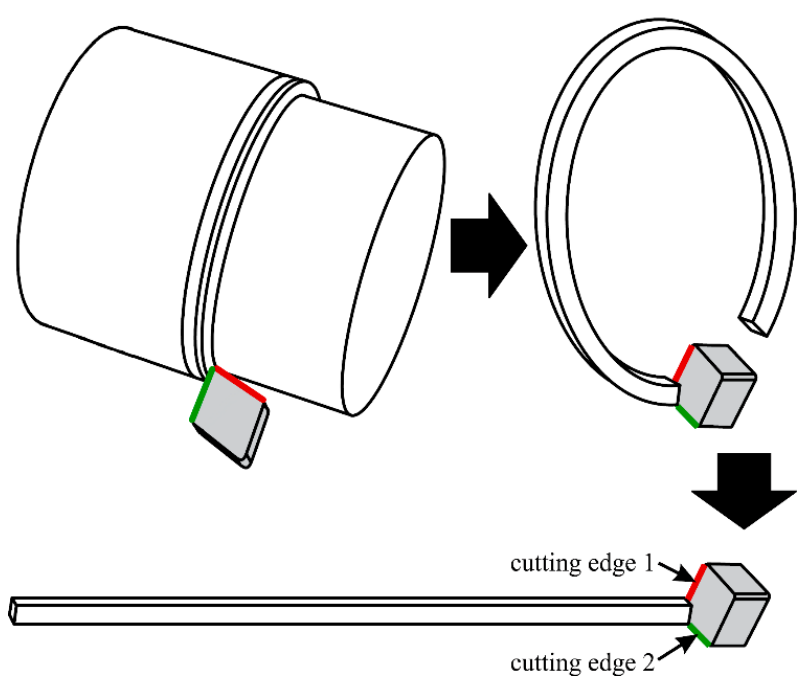

Fig. 5 Illustration of the 3D-2D projection
Since no 3D CAD geometry of the insert was available, the insert was 3D-scanned with a precise dental scanner. The scanned geometry is shown in the Fig. 6. Afterwards, the 3D model of the insert was built based on the point cloud. The final geometry of the tool in the 2D model was obtained by creating a cross-section of the model with a properly positioned plane. This plane was defined based on the knowledge of the machining arrangement.

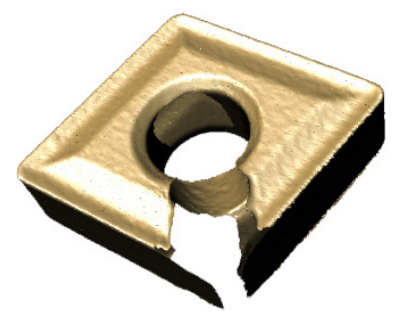

Fig. 6 3D-scanned geometry of the cutting insert

The Fig. 7 shows the basic geometry of the used FE model with the applied boundary conditions, where cutting takes place in the XY plane under plane strain condition.

In the simulations, the workpiece is divided into three layers. The upper layer of the workpiece is the chip layer (S1), which is separated from the other part of the workpiece (S3) by a sacrificial element layer (S2) positioned based on the previously presented projection $(f)$. When the tool approaches a sacrificial element, it will be deleted based on a damage criterion [12].

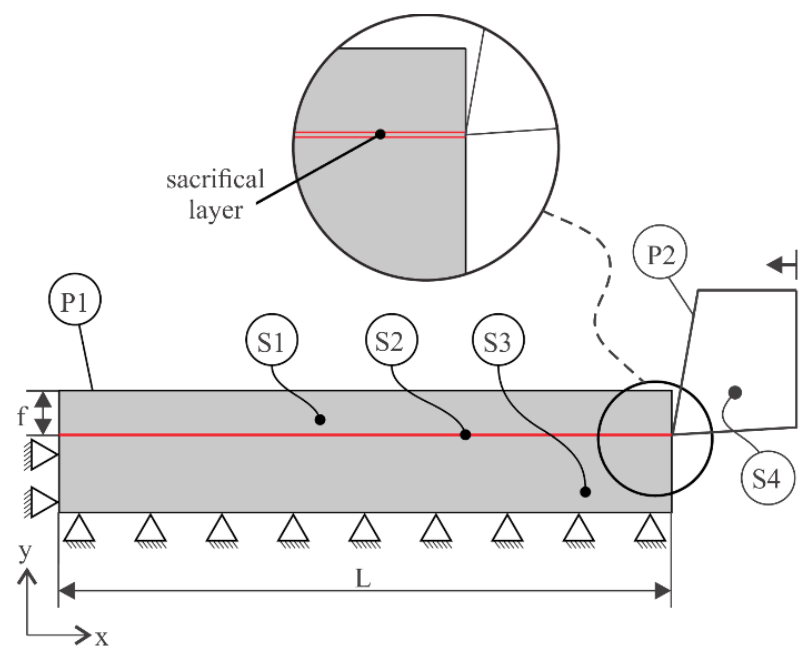

Fig. 7 FE model for the 2D simulation

The cutting edge of the tool was positioned to the sacrificial layer of the workpiece geometry.

For the workpiece, an encastre boundary condition was applied to the lower edge, and to the left edge of the third section (S3). The upper and the right edges of the tool in the $\mathrm{y}$-direction are fixed and there is a displacement type boundary condition given along the $\mathrm{x}$-direction which equals the length of the workpiece $(L)$. 


\subsection{Mesh}

The applied mesh consisted of CPE4RT elements with plane strain condition. On S1 and S2 relaxed stiffness, while on S3 and S4 enhanced hourglass control was selected. Distortion control was applied on every section except for S1, where ALERemeshing was used with frequency of 50000 and 5 remeshing sweeps per increment. Its usage prevented overly distorted mesh. Element deletion was allowed only in the sacrificial layer.

Three different chip thicknesses were simulated -0.355 , 0.18 and $0.09 \mathrm{~mm}$. The length of the workpiece in every model was set proportionally to its thickness. In each case, the element size was set according to the sensitivity analysis detailed in Section 3.6. This mesh yielded satisfactory results with favourable computational time.

The contact of the tool and workpiece was modelled with a surface-to-node interaction. The master surface and slave nodes are highlighted in Fig. 8. Finite sliding was applied, the exact properties are defined in Section 3.5.

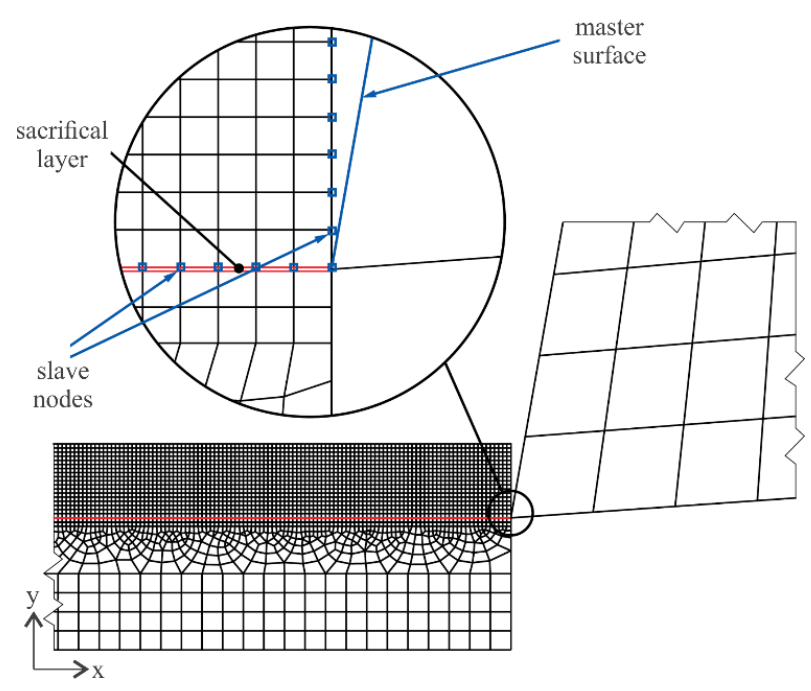

Fig. 8 Illustration of the mesh structure

\subsection{Material model}

\subsubsection{Workpiece - AISI 1045}

Similarly to most of the literature on the topic [13-28], the AISI 1045 steel workpiece was modelled with the JohnsonCook material model [29]. The popularity of this model is due to its capability of describing behaviour of metals in processes where large strains, high strain rates, temperature dependency and visco-plastic deformation are included.

The properties of the Johnson-Cook constitutive model are best represented by the expression for equivalent stress:

$$
\bar{\sigma}=\underbrace{\left[A+B\left(\bar{\varepsilon}^{p l}\right)^{n}\right]}_{\text {Elastoplastic }} \underbrace{\left[1+C \ln \left(\frac{\dot{\bar{\varepsilon}}^{p l}}{\dot{\varepsilon}_{0}}\right)\right]}_{\text {Viscosity }} \underbrace{\left[1-\left(\frac{T-T_{r}}{T_{m}-T_{r}}\right)^{m}\right],}_{\text {Thermal softening }}
$$

where $A$ is the yield strength, $B$ is the hardening modulus, $C$ is the coefficient of strain rate sensitivity, $n$ is the hardening coefficient, $m$ is the thermal softening coefficient, $T_{m}, T_{r}, T$ are the melting, room and current temperature respectively, $\dot{\varepsilon}_{0}$ is the reference plastic strain rate. The values of these parameters for the investigated AISI 1045 steel are taken from the literature $[22,25,26,30]$, and can be found in Table 5 .

Disruption of the finite element mesh is necessary for modelling chip formation, therefore besides the material model, the Johnson-Cook damage model was also applied. This is a fracture model for ductile materials and consists of two phases, a damage initiation and a damage evolution phase.

The Johnson-Cook damage model assumes that the equivalent strain at failure is of the form:

$$
\bar{\varepsilon}_{f}=\left[D_{1}+D_{2} \exp \left(D_{3} \frac{p}{\bar{\sigma}}\right)\right]\left[1+D_{4} \ln \left(\frac{\dot{\bar{\varepsilon}}^{p l}}{\dot{\varepsilon}_{0}}\right)\right]\left[1+D_{5}\left(\frac{T-T_{r}}{T_{m}-T_{r}}\right)\right]
$$

where the values of constant coefficients are taken from the literature [11] and are presented in Table 6. In each increment of the simulation, the increment of the equivalent strain $\Delta \bar{\varepsilon}^{p l}$ is calculated. The fraction damage is initiated in an element when the cumulative damage parameter

$$
\omega=\sum \frac{\Delta \bar{\varepsilon}^{p l}}{\bar{\varepsilon}_{f}}
$$

exceeds the value of 1 .

The stress-strain relation of damaged material is illustrated in Fig. 9, where $\sigma_{y 0}$ and $\bar{\varepsilon}_{0}^{p l}$ are the yield stress and equivalent plastic strain at the onset of damage, and $\bar{\varepsilon}_{f}^{p l}$ is the equivalent plastic strain at failure; that is, when the overall damage variable reaches the value $D=1$. The overall damage variable $D$ captures the effect of damage mechanisms. The value of the equivalent plastic strain at failure $\bar{\varepsilon}_{f}^{p l}$ depends on the characteristic length of the element and cannot be used as a material parameter for the specification of the damage evolution law. Instead, the damage evolution law is specified in terms of fracture energy dissipation $G_{f}$, a material parameter that shows the required energy to open a unit area of crack [31].

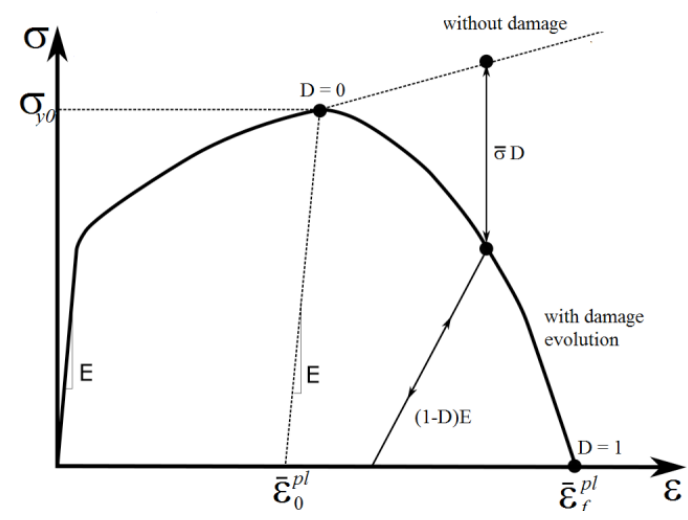

Fig. 9 Stress-strain curve with damage degradation [31] 
The value of $G_{f}$ depends on how the crack evolves. Two types of crack development are described in the literature, illustrated in Fig. 10. In the sacrificial layer, the first mode, while in the chip layer, the second mode is considered as the dominant one. Therefore, the value for the fracture energy of these two sections are determined by the corresponding fracture toughness $K_{f}$ according to the following expression:

$$
G_{f, i}=\frac{1-v^{2}}{E} K_{f, i}^{2}
$$

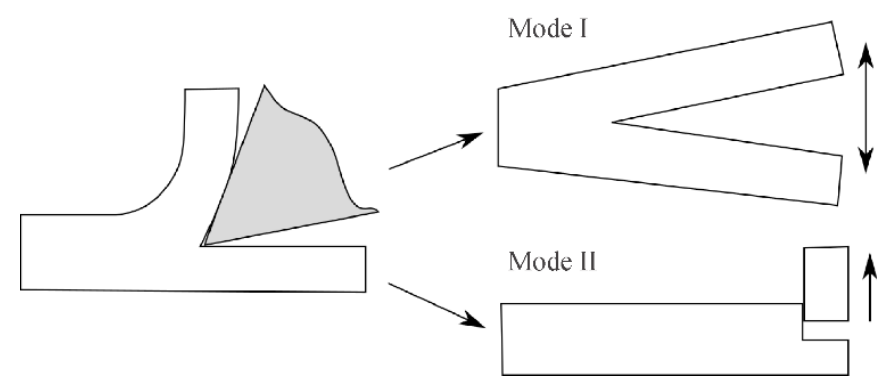

Fig. 10 Illustration of fracture modes I and II

\subsubsection{Tool}

To obtain temperature field results, the tool material is specified as a linearly elastic material with thermal properties. Material properties are summarized in Table 4.

Table 4 General material properties for AISI 1045 workpiece, and coated carbide tool

\begin{tabular}{lll}
\hline Material parameter & Workpiece AISI 1045 & Tool \\
\hline Density $\left[\mathrm{kg} / \mathrm{m}^{3}\right]$ & 7800 & 4940 \\
Young's modulus [GPa] & 200 & 450 \\
Poisson's ratio [1] & 0.3 & 0.18 \\
Specific heat $\left[\mathrm{J} /\left(\mathrm{kg}^{\circ} \mathrm{C}\right)\right]$ & 486 & 565.15 \\
Thermal conductivity $\left[\mathrm{W} /\left(\mathrm{m}^{\circ} \mathrm{C}\right)\right]$ & 49.8 & 30.9 \\
Expansion $\left[\mu \mathrm{m} /\left(\mathrm{m}^{\circ} \mathrm{C}\right)\right]$ & 11.5 & 7.7 \\
Melting temperature $\left[{ }^{\circ} \mathrm{C}\right]$ & 1460 & - \\
Room temperature $\left[{ }^{\circ} \mathrm{C}\right]$ & 25 & 25 \\
Fracture toughness $-\mathrm{mode} \mathrm{I.}$ & 55.4 & - \\
Fracture toughness - mode II. & 71.5 & - \\
\hline
\end{tabular}

Table 5 Johnson-Cook material parameters

\begin{tabular}{lllll}
\hline $\mathrm{A}[\mathrm{MPa}]$ & $\mathrm{B}[\mathrm{MPa}]$ & $\mathrm{C}[1]$ & $\mathrm{n}[1]$ & $\mathrm{m}[1]$ \\
\hline 553.1 & 600.8 & 0.0134 & 0.234 & 1 \\
\hline
\end{tabular}

Table 6 Johnson-Cook damage coefficients

\begin{tabular}{llllll}
\hline $\mathrm{D}_{1}$ & $\mathrm{D}_{2}$ & $\mathrm{D}_{3}$ & $\mathrm{D}_{4}$ & $\mathrm{D}_{5}$ & $\dot{\varepsilon}_{0}\left[\mathrm{~s}^{-1}\right]$ \\
\hline 0.05 & 4.22 & -2.73 & 0.0018 & 0.55 & 1 \\
\hline
\end{tabular}

\subsection{Modified Coulomb Friction}

Frictional interaction was considered in the FE simulation in order to get the most realistic results. The frictional interaction between the chip and the cutting tool is modeled with a modified Coulomb friction law [32].

If the shear stress is denoted by $\tau$ and the normal pressure by $p$ then the critical friction stress is determined by

$$
\tau_{C}=\min \left(\mu p, \tau_{\text {limit }}\right)
$$

where $\mu$ is the friction coefficient and $\tau_{\text {limit }}$ is the shear stress limit. The modified Coulomb friction law states that slip occurs at the contact point when the shear stress is greater than $\tau_{C}$ which is the critical shear stress.

However, it is difficult to identify the friction coefficient at the tool-chip contact. Based on the experiences of many previous authors $[11,25]$, the friction coefficient was set to 0.17 .

\subsection{Sensitivity analyses}

Though the literature of cutting simulation is extensive, there are several parameters (material constants, simulation settings, quantities describing contact behaviour) that were determined empirically. It is important to mention that the use of empirically obtained parameters causes that the expectations influence the results. Uniformed description of machining processes cannot be derived.

In this study, several such parameters were examined, which were different in various sources. Sensitivity analyses were performed to examine the influence of specific parameters on the reaction force. The simulations were performed with changing only one of the parameters, and all other settings remained the same.

Thus the effect of certain parameters could be examined individually.

\subsubsection{Mesh dependency}

The most important concern was the effect of mesh size. Three different simulations were performed with different element sizes $(0.05,0.02,0.008 \mathrm{~mm})$. The influence of the element sizes on the reaction forces in $\mathrm{x}$-direction can be seen in Fig. 11.

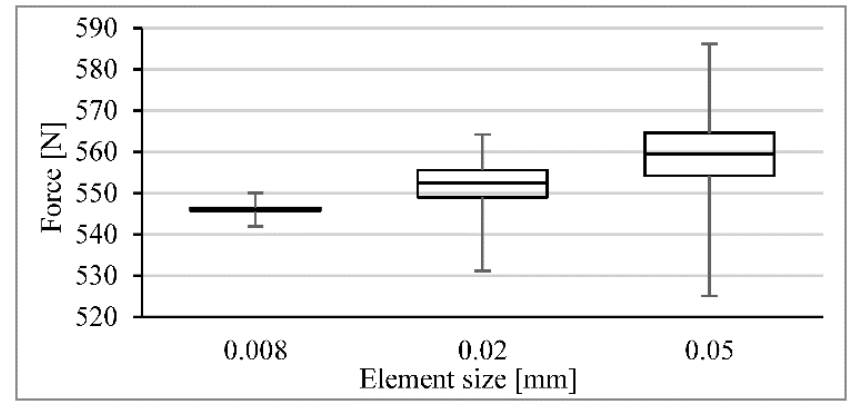

Fig. 11 Variation of the reaction forces in $\mathrm{x}$-direction in terms of the applied element size 
In general, it can be observed that the reduction of the element size decreases the deviance of the force values. Moreover, the reaction force will be smaller with reduced element size. This indicates that the finite element model gives an upper estimation on the reaction force.

The average force with elements of size $0.008 \mathrm{~mm}$ is around $98 \%$ of the value registered with elements of size $0.02 \mathrm{~mm}$. Since simulation time was rapidly increasing with mesh refinement, furthermore, the deviation in the measured force signal is large, this inaccuracy is acceptable. Therefore $0.02 \mathrm{~mm}$ element size was applied for analyses with chip thickness of $0.355 \mathrm{~mm}$. For simulations corresponding to different chip thicknesses, proportional mesh was employed.

\subsubsection{Mass scaling}

The necessary computational cost could be further reduced by using the mass scaling technique. However, this influences the resulting force signal, therefore a sensitivity analysis was performed.

Semi-automatic mass scaling was applied for the whole model with the following fixed scaling factors: 1, 5, 10, 20, 50, 100 .

The effect of the mass scaling factors on the resulting force is presented in Fig. 12. The average value of the reaction force does not change significantly, and the deviation increases only in the transient phase with greater mass scaling factors.

It can be declared that applying mass scaling factor 20 in the simulations has a negligible effect on the results.

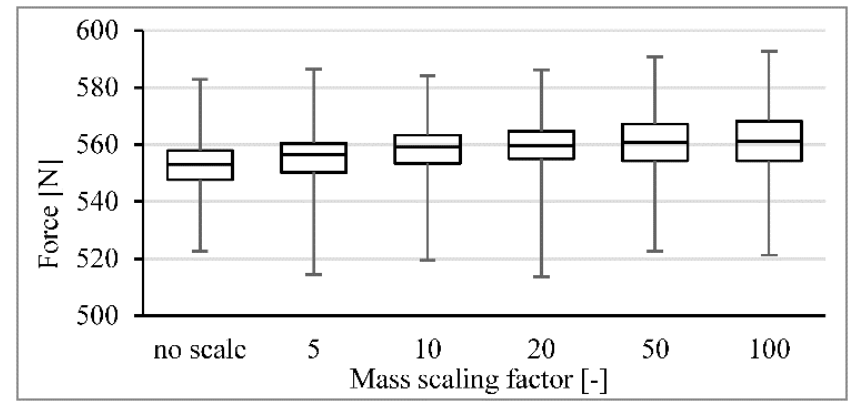

Fig. 12 Effect of the mass scaling on the reaction force

\subsubsection{Rake angle}

Other significant parameter of the cutting process was the rake angle. To investigate the influence of tool geometry, eight simulations were performed with different rake angles. The results were summarized in Table 7 . It was observed that the accurate geometry is indispensable in order to build a realistic simulation because the geometry of the tool has remarkable effect on the results. In Fig. 13, the comparison of the reaction forces is shown regarding to three different rake angles.

The rake angle may have negative value in cutting processes. The effect of the negative rake angle on the cutting forces is investigated in [33-35], for instance.
Table 7 Averaged forces with respect to the rake angle

\begin{tabular}{ll}
\hline Rake angle, $\left[{ }^{\circ}\right]$ & Average force, $[\mathrm{N}]$ \\
\hline 20 & 305.1 \\
18 & 321.9 \\
16 & 342.8 \\
14 & 368.8 \\
12 & 384.9 \\
10 & 408.3 \\
8 & 424.8 \\
0 & 501.6 \\
\hline
\end{tabular}

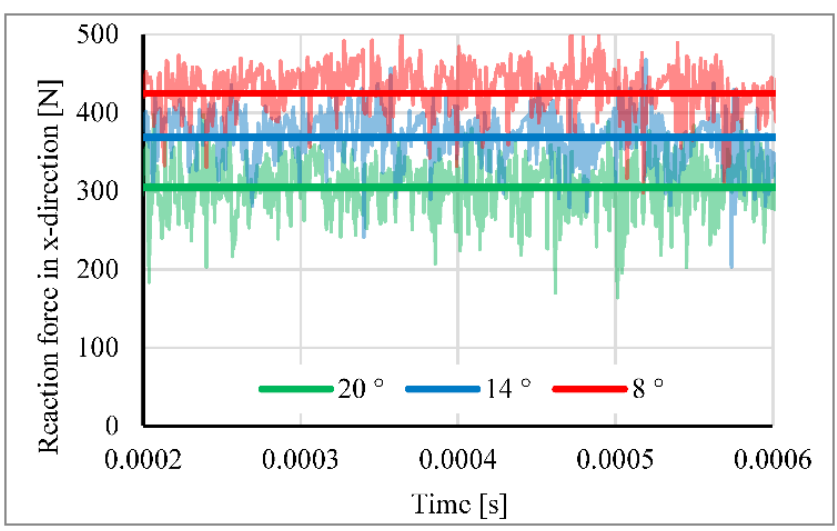

Fig. 13 Results of the rake angle sensitivity

It was identified that the correlation between the rake angle and the cutting force is approximately linear as it can be seen in Fig. 14.

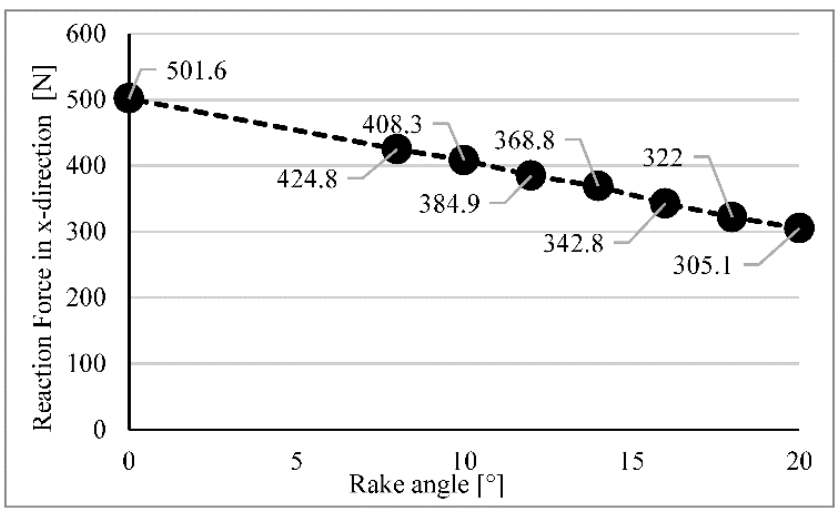

Fig. 14 Averaged forces with respect to the rake angle

\subsubsection{Contact - Friction coefficient}

As it has already been mentioned, the friction coefficient at the tool-chip contact is difficult to identify. Thus, sensitivity analysis was also performed to investigate the effect of the different friction coefficients on the reaction forces and the heat generation. The considered parameters and the results for the reaction force in $\mathrm{x}$-direction are presented in Table 8 and in Fig. 15. 
Table 8 Averaged forces with respect to the frictional coefficient

\begin{tabular}{ll}
\hline Friction coefficient $\mu$ & Averaged force $[\mathrm{N}]$ \\
\hline 0 & 469.1 \\
0.1 & 516.2 \\
0.17 & 552.1 \\
0.2 & 568.2 \\
0.3 & 625.1 \\
\hline
\end{tabular}

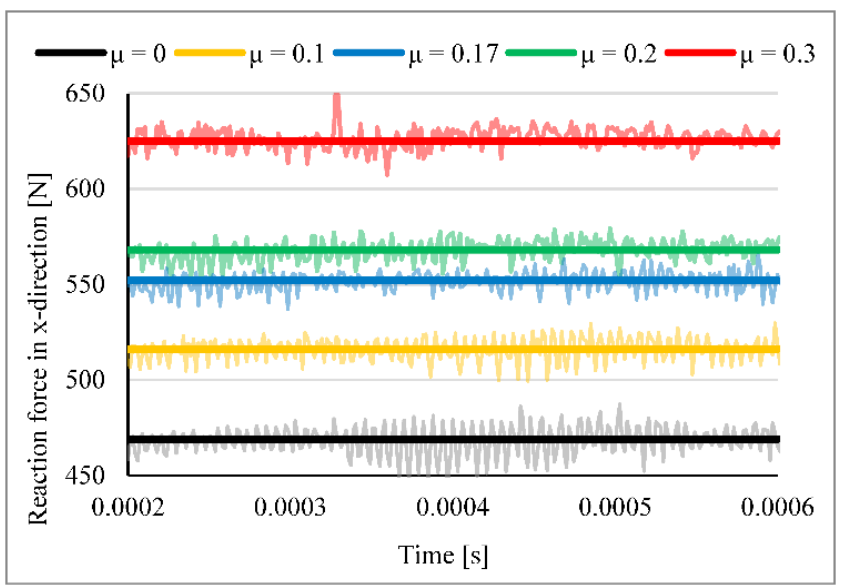

Fig. 15 Results of the friction coefficient sensitivity

\section{Results and comparison}

\subsection{Evaluation of the simulation}

As an illustration the von Mises stress distribution and the temperature distribution can be seen on Fig. 16 and Fig. 17 for one specific simulation setup.

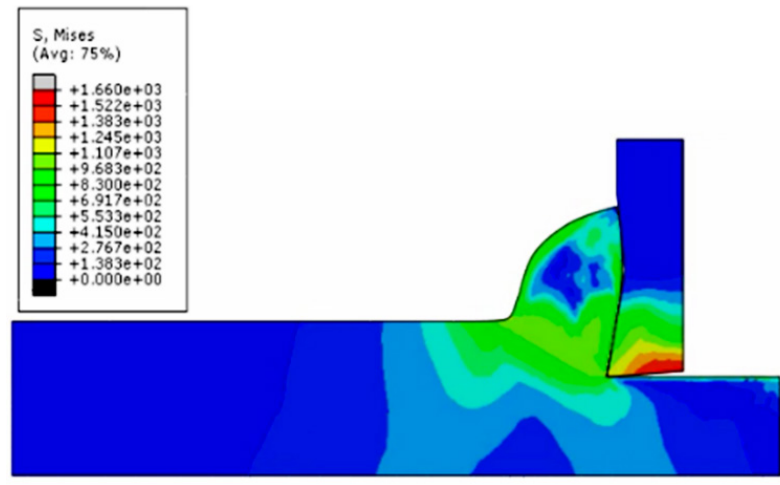

Fig. 16 Mises equivalent stress distribution

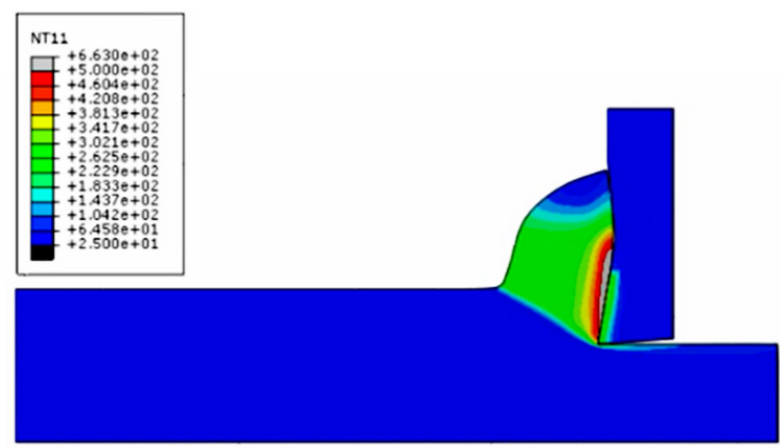

Fig. 17 Nodal temperature distribution
The reaction force in the tangential direction against time is shown in Fig. 18 and Fig. 20. Dimensionless time is used, since different time intervals are assigned to different simulations.

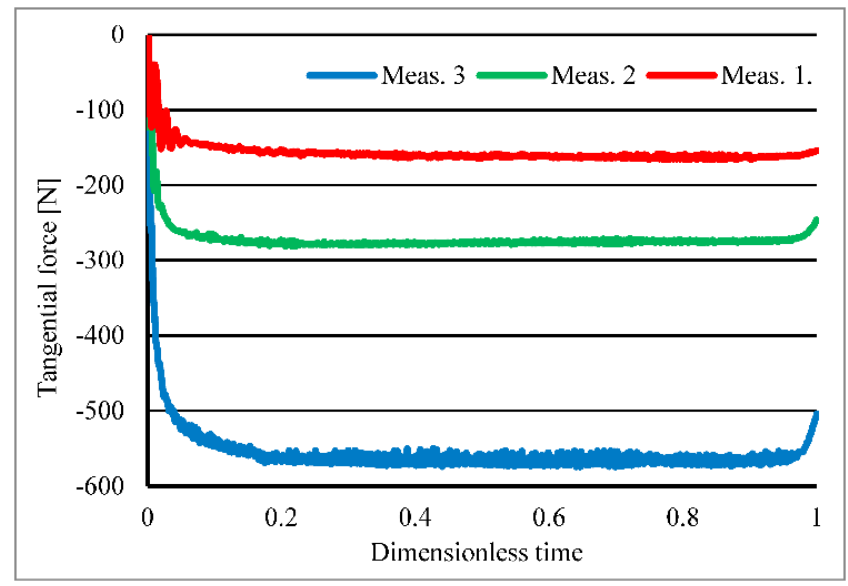

Fig. 18 Results of the simulations \#1-3

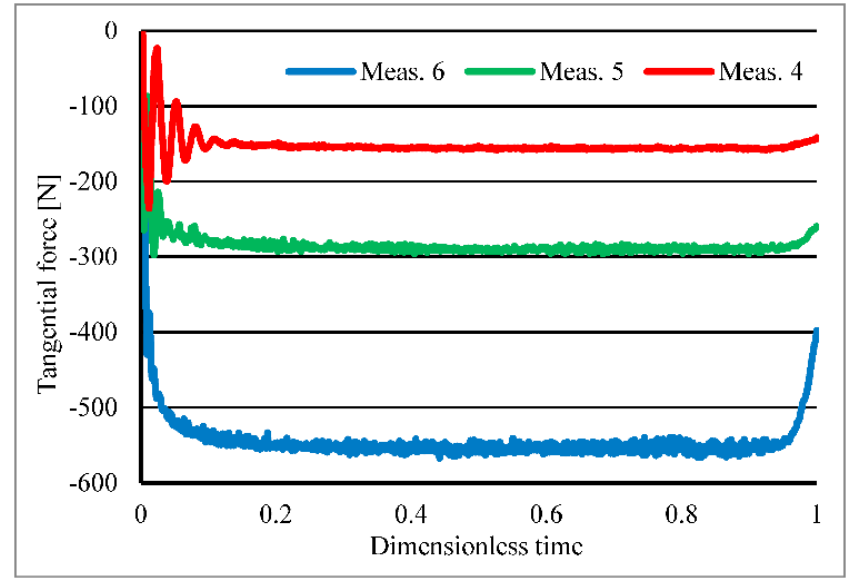

Fig. 19 Results of the simulations \#4-6

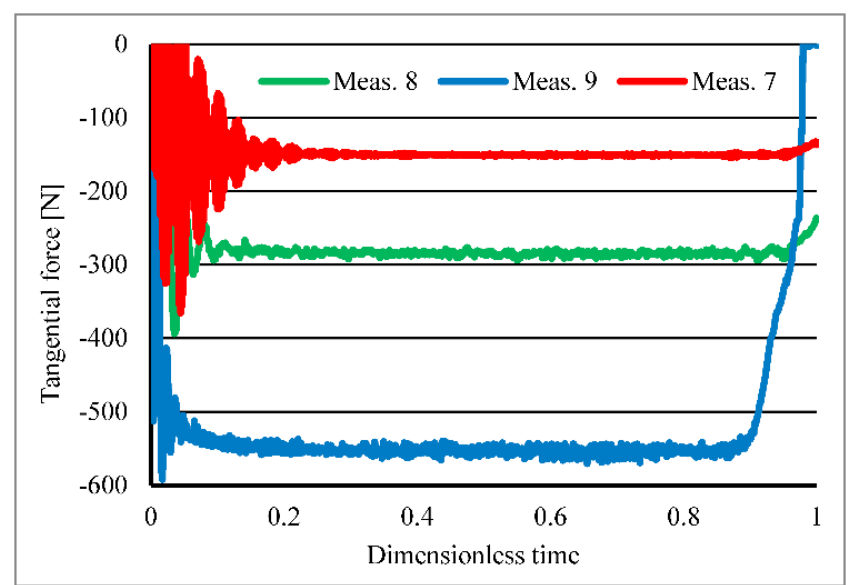

Fig. 20 Results of the simulation \#7-9

Ignoring the transient part of the results, the steady state reaction force values can be compared to the measurement data.

\subsection{Comparison with the measurement data}

The measurement and simulation data are presented in Table 9 and in Fig. 21-Fig. 23. 


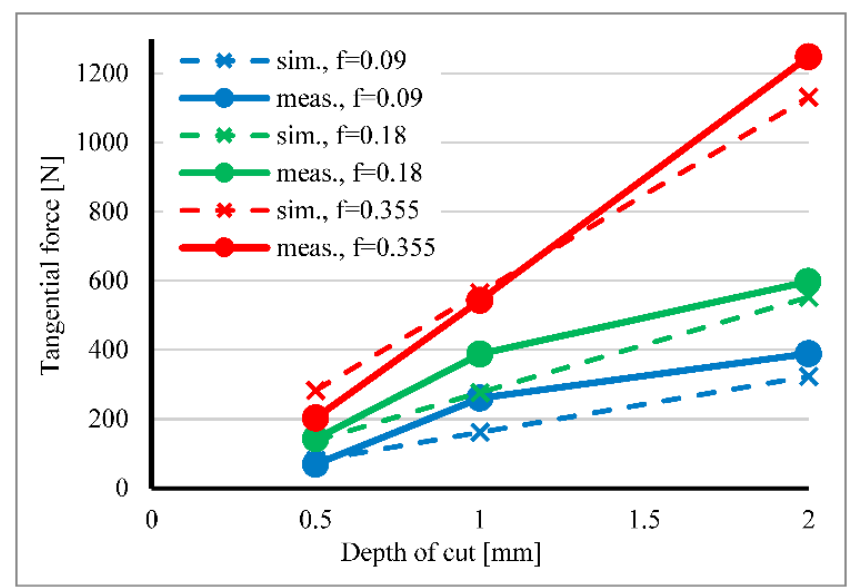

Fig. 21 Comparison of the results for $\mathrm{n}=1001 / \mathrm{min}$

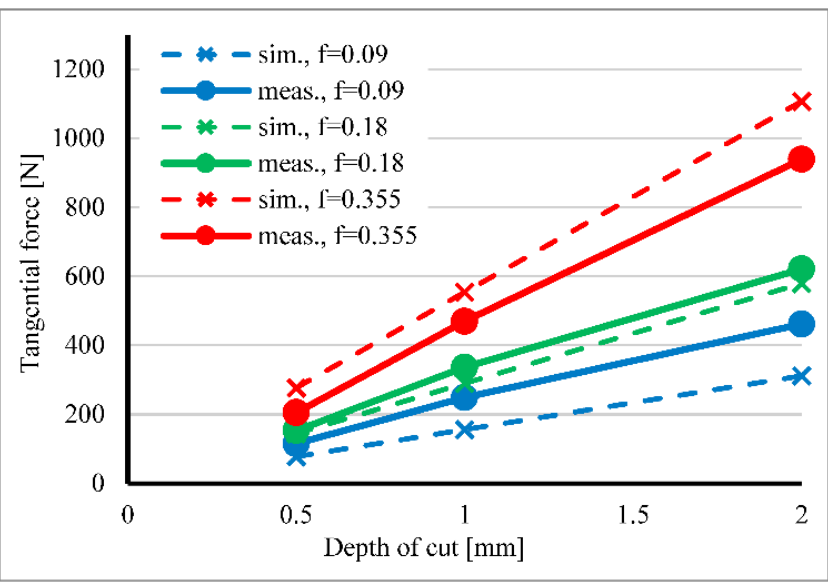

Fig. 22 Comparison of the results for $\mathrm{n}=2001 / \mathrm{min}$

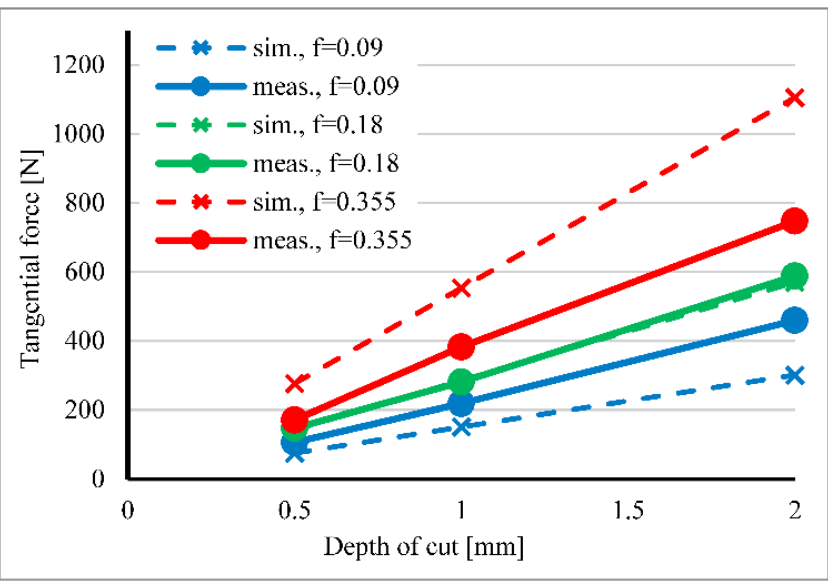

Fig. 23 Comparison of the results for $\mathrm{n}=3001 / \mathrm{min}$

In $\mathrm{x}$-direction, the average error of the results is $23 \%$, the maximal error is $61.7 \%$.

\section{Conclusion}

The aim of this study was to present a general overview of the possibilities of 2D finite element simulations of metal cutting processes by comparing the results of the computational analyses to formerly executed measurements.

The measurement setup and recorded results were discussed then a possible projection of the examined 3D turning process to a $2 \mathrm{D}$ ABAQUS model was introduced. A working finite element model was built up in ABAQUS/Explicit. The parameter dependency of this model was investigated via sensitivity analyses, where the effects of varying element size, mass scaling factor, friction coefficient, rake angle were presented. Using the conclusions of these investigations, an effective model was built up which involves as limited approximations as possible, and has favourable computational properties.

Table 9 Results of the simulations

\begin{tabular}{|c|c|c|c|c|c|c|}
\hline \# & $\begin{array}{l}\mathrm{F}_{\mathrm{r}} \\
{[\mathrm{N}]}\end{array}$ & $\begin{array}{l}\mathrm{F}_{\mathrm{t}} \\
{[\mathrm{N}]}\end{array}$ & $\begin{array}{l}\mathrm{F}_{\mathrm{x}} \\
{[\mathrm{N}]}\end{array}$ & $\begin{array}{l}\text { Relative } \\
\text { error } \\
{[\%]}\end{array}$ & $\begin{array}{l}\mathrm{F}_{\mathrm{y}} \\
{[\mathrm{N}]}\end{array}$ & $\begin{array}{l}\text { Relative } \\
\text { error } \\
{[\%]}\end{array}$ \\
\hline 1 & 77.7 & 69.6 & 80.8 & 16.1 & 0.2 & -99.7 \\
\hline 2 & 159.9 & 142.8 & 138.1 & -3.7 & 0.4 & -99.7 \\
\hline 3 & 289.7 & 203.2 & 282.8 & 39.2 & 3.5 & -98.7 \\
\hline 4 & 107.5 & 115.6 & 77.8 & -32.7 & 0.1 & -99.9 \\
\hline 5 & 161.9 & 153.1 & 144.8 & -5.4 & 0.3 & -99.8 \\
\hline 6 & 284.6 & 204.5 & 276.8 & 35.3 & 1.0 & -99.6 \\
\hline 7 & 90.4 & 106.3 & 75.3 & -29.2 & 0.1 & -99.9 \\
\hline 8 & 148.6 & 147.2 & 142.5 & -3.2 & 0.1 & -99.9 \\
\hline 9 & 230.9 & 170.9 & 276.4 & 61.7 & 0.2 & -99.9 \\
\hline 10 & 135.7 & 259.1 & 161.6 & -37.8 & 0.4 & -99.7 \\
\hline 11 & 232.7 & 388.8 & 276.2 & -28.8 & 0.8 & -99.6 \\
\hline 12 & 431.6 & 543.3 & 565.7 & 4.1 & 7.0 & -98.3 \\
\hline 13 & 144.7 & 248.0 & 155.6 & -37.3 & 0.1 & -99.9 \\
\hline 14 & 217.5 & 336.4 & 289.7 & -13.9 & 0.8 & -99.6 \\
\hline 15 & 399.2 & 468.9 & 553.5 & 18.1 & 1.9 & -99.5 \\
\hline 16 & 129.6 & 218.8 & 150.6 & -31.2 & 0.2 & -99.8 \\
\hline 17 & 186.0 & 280.7 & 285 & 1.5 & 0.2 & -99.9 \\
\hline 18 & 321.9 & 382.1 & 552.8 & 44.6 & 0.3 & -99.9 \\
\hline 19 & 157.4 & 389.1 & 323.1 & -16.9 & 0.7 & -99.6 \\
\hline 20 & 248.3 & 597.8 & 552.3 & -7.6 & 1.5 & -99.4 \\
\hline 21 & 571.0 & 1248.6 & 1131.3 & -9.4 & 14.0 & -97.6 \\
\hline 22 & 154.5 & 461.4 & 311.2 & -32.5 & 0.1 & -99.9 \\
\hline 23 & 246.2 & 620.9 & 579.4 & -6.7 & 1.5 & -99.4 \\
\hline 24 & 456.1 & 939.2 & 1107 & 17.8 & 3.8 & -99.2 \\
\hline 25 & 141.5 & 459.2 & 301.1 & -34.4 & 0.3 & -99.8 \\
\hline 26 & 231.7 & 588.1 & 570 & -3.1 & 0.2 & -99.9 \\
\hline 27 & 363.5 & 747.0 & 1105.5 & 47.9 & 0.6 & -99.8 \\
\hline
\end{tabular}

The finalized model was used with the machining parameters (feed rate, frequency, depth of cut) that correspond to the measurements. The experimental and computed results were compared.

As a conclusion of the comparison it can be said that the simulated reaction forces in the $\mathrm{x}$-direction and the measured tangential reaction forces are well correlating for different cutting parameters - the average error was $23 \%$. This is a major 
achievement since the parameters of the model were not fitted to the experimental data. However, the simulated y-directional reaction forces have substantial error compared to the measurements: the authors do not recommend the use of two dimensional finite element analysis to estimate cutting forces in the radial and axial directions of straight turning.

The most significant difficulties of the 2D simulations come from the lack of side cutting edge, and nose radius of the tool. Three dimensional analysis could take account of the resultant forces of the side cutting edge of the tool, and could model the cross section of the chip properly, as other authors have already demonstrated [35].

\section{Acknowledgement}

The research leading to these results has received funding from the European Research Council under the European Union's Seventh Framework Programme (FP/2007-2013)/ERC Advanced Grant Agreement n. 340889.

\section{References}

[1] Ducobu, F., Rivière-Lorphèvre, E., Filippi, E. "Numerical contribution to the comprehension of saw-toothed Ti6Al4V chip formation in orthogonal cutting." International Journal of Mechanical Sciences. 81, pp. 7787. 2014. https://doi.org/10.1016/j.ijmecsci.2014.02.017

[2] Sun, S., Brandt, M., Dargusch, M. S. "Characteristics of cutting forces and chip formation in machining of titanium alloys." International Jouurnal of Machine Tools and Manufacture. 49(7-8), pp. 561-568. 2009. https://doi.org/10.1016/j.ijmachtools.2009.02.008

[3] Ducobu, F., Rivière-Lorphèvre, E., Filippi, E. "On the introduction of adaptive mass scaling in a finite element model of Ti6Al4V orthogonal cutting." Simulation Modelling Practice and Theory. 53, pp. 1-14. 2015. https://doi.org/10.1016/j.simpat.2015.02.003

[4] Hokka, M., Gomon, D., Shrot, A., Leemet, T., Bäker, M., Kuokkala, V.T. "Dynamic Behavior and High Speed Machining of Ti-6246 and Alloy 625 Superalloys: Experimental and Modeling Approache." Experimental Mechanics. 54(2), p. 199-210. 2014.

https://doi.org/10.1007/s11340-013-9793-7

[5] Ljustina, G., Fagerström, M., Larsson, R. "Rate Sensitive Continuum Damage Models and Mesh Dependence in Finite Element Analyses." The Scientific World Journal. 2014. Article ID 260571, 8 pages. https://doi.org/10.1155/2014/260571

[6] Menezes, P. L., Avdeev, I. V., Lovell, M. R., Higgs, C. F. III. "An explicit finite element model to study the influence of rake angle and friction during orthogonal metal cutting." International Journal of Advanced Manufacruring Technology. 73(5), p. 875-885. 2014.

https://doi.org/10.1007/s00170-014-5877-5

[7] Parle, D., Singh, R. K., Joshi, S. S., Ravikumar, G. V. V. "Modeling of microcrack formation in orthogonal machining." International Journal of Machine Tools and Manufacture. 80-81, pp. 18-29. 2014. https://doi.org/10.1016/j.ijmachtools.2014.02.003

[8] Preś, P., Skoczyński, W., Jaśkiewicz, K. "Research and modeling workpiece edge formation process during orthogonal cutting." Archives of civil and mechanical engineering. 14(5), pp. 622-635. 2014. https://doi.org/10.1016/j.acme.2014.01.003
[9] Wang, B., Liu, Z. "Investigations on the chip formation mechanism and shear localization sensitivity of high-speed machining Ti6Al4V." International Journal of Advanced Manufaturing Technology. 75(5), pp. 1065-1076. 2014. https://doi.org/10.1007/s00170-014-6191-y

[10] Xi, Y., Bermingham, M., Wang, G., Dargusch, M. "SPH/FE modeling of cutting force and chip formation during thermally assisted machining of Ti6Al4V alloy." Computational Materials Science. 84, pp. 188-197. 2014. https://doi.org/10.1016/j.commatsci.2013.12.018

[11] Vaziri, M. R., Salimi, M., Mashayekhi, M. "A new calibration method for ductile fracture models as chip separation criteria in machining."Simulation Modelling Practice and Theory. 18(9), pp. 1286 1296, 2010. https://doi.org/10.1016/j.simpat.2010.05.003

[12] Asad, M. "Elaboration of concepts and methodologies to study peripheral down-cut milling process from macro-to-micro scales." Thesis, Institut National Des Sciences Appliquees De Lyon. 2010. URL: http:// theses.insa-lyon.fr/publication/2010ISAL0058/these.pdf

[13] Ng, E.-U., Aspinwall, D. K. "Modelling of hard part machining." Journal of Materials Processing Technology. 127(2), pp. 222-229. 2002. https://doi.org/10.1016/S0924-0136(02)00146-2

[14] Arrazola, P. J., Meslin, F., Hamann, J.-C., Le Maître, F. "Numerical Cutting Modeling with Abaqus/Explicit 6.1." [Performance]. ABAQUS Users' Conference, 2002.

[15] Guo, Y. B., Yen, D. W. "A FEM study on mechanisms of discontinuous chip formation in hard machining." Journal of Materials Processing Technology. 155-156, pp. 1350-1356. 2004. https://doi.org/10.1016/j.jmatprotec.2004.04.210

[16] Pantalé, O., Bacaria, J.-L., Dalverny, O., Rakotomalala, R.. Caperaa, S. "2D and 3D numerical models of metal cutting with damage effects." Computer Methods in Applied Mechanics and Engineering. 193(39-41), pp. 4383-4399. 2004. https://doi.org/10.1016/j.cma.2003.12.062

[17] Arrazola, P. J., Ugarte, D., Montoya, J., Villar, A., Marya, S. "Finite element modeling of chip formation process with ABAQUS/Explicit 6.3." [Performance].VIII International Conference on Computational Plasticity, 2005. URL: http://congress.cimne.upc.es/complas05/admin/ Files/FilePaper/p173.pdf

[18] Asad, M., Mabrouki, T., Rigal, J. F. "Finite-element-based hybrid dynamic cutting model for aluminium alloy milling." Proceedings of the Institution of Mechanical Engineers, Part B: Journal of Engineering Manufacture. 224(1), pp. 1-13. 2010. https://doi.org/10.1243/09544054JEM1590

[19] Duan, C. Z., Dou, T., Cai, Y. J., Li, Y. Y. "Finite Element Simulation and Experiment of Chip Formation Process during High Speed Machining of AISI 1045 Hardened Steel." International Journal of Recent Trends in Engineering. 1(5), pp. 46-50. 2009.

https://doi.org/10.4028/www.scientific.net/AMM.29-32.1838

[20] Miguélez, M. H., Munoz-Sanchez, A., Cantero, J. L., Loya, J. A. "An efficient implementation of boundary conditions in an ALE model for orthogonal cutting." Journal of Theoretical and Applied Mechanics. 47(3), pp. 599-616. 2009. URL: http://www.ptmts.org.pl/Miguelez-MSC-L-3-09.pdf

[21] Wu, J., Han, R. D. "A new approach to predicting the maximum temperature in dry drilling based on a finite element model." Journal of Manufacturing Processes. 11(1), pp. 19-30. 2009. https://doi.org/10.1016/j.jmapro.2009.07.001

[22] Woon, K.-S., Rahman, M., Liu, K. "Numerical and Experimental Study of Contact Behavior in the Tool-based Micromachining of Steel." International Journal of Precision Engineering and Manufacturing. 11(3), pp. 453-459. 2010. https://doi.org/10.1007/s12541-010-0052-X 
[23] Abushawashi, Y., Xiao, X., Astakhov, V. P. "FEM simulation of motel cutting using a new approach to model chip formation." International Journal of Advances in Machining and Forming Operations. 3(2), pp. 71-92. 2011.

[24] Duan, C. Z., Dou, T., Cai, Y. J., Li, Y. Y. "Finite Element Simulation and Experiment of Chip Formation Process during High Speed Machining of AISI 1045 Hardened Steel." International Journal of Recent Trends in Engineering. 1(5), pp. 46-50.

[25] Courbon, C., Mabrouki, T., Rech, J., Mazuyer, D., D’Eramo, E. "On the existence of a thermal contact resistance at the tool-chip interface in dry cutting of AISI 1045: Formation mechanisms and influence on the cutting process." Applied Thermal Engineering. 50(1), pp. 1311-1325. 2013. https://doi.org/10.1016/j.applthermaleng.2012.06.047

[26] Duan, C., Zhang, L. "A reliable method for predicting serrated chip formation in high-speed cutting: analysis and experimental verification." The International Journal of Advanced Manufactoring Technology. 64(9), pp. 1587-1597. 2013. https://doi.org/10.1007/s00170-012-4125-0

[27] Jin, X., Altintas, Y. "Prediction of micro-milling forces with finite element method." Journal of Materials Processing Technology. 212(3), pp. 542-552. 2012. https://doi.org/10.1016/j.jmatprotec.2011.05.020

[28] Ma, W., Li, X., Dai, L., Ling, Z. "Instability criterion of materials in combined stress states and its application to orthogonal cutting process." International Journal of Plasticity. 30-31, pp. 18-40. 2012. https://doi.org/10.1016/j.ijplas.2011.09.003

[29] Johnson, G. R., Cook, H. W. "Fracture characteristics of three metals subjected to various strains, strain rates, temperatures and pressures." Engineering Fracture Mechanics. 21(1), pp. 31-48. 1985. https://doi.org/10.1016/0013-7944(85)90052-9
[30] Vaziri, M. R., Salimi, M., Mashayekhi, M. "Evaluation of chip formation simulation models for material separation in the presence of damage models." Simulation Modelling Practice and Theory. 19(2), pp. 718-733. 2011. https://doi.org/10.1016/j.simpat.2010.09.006

[31] ABAQUS, ABAQUS Documentation, Providence, RI, USA: DassaultSystémes, 2011.

[32] Shet, C., Deng, X. "Finite element analysis of the orthogonal metal cutting process." Journal of Materials Processing Technology. 105(1-2), pp. 95-109. 2000. https://doi.org/10.1016/S0924-0136(00)00595-1

[33] Gok, K., Sari, H., Gok, A., Neseli, S., Turkes, E., Yaldiz, S. "Threedimensional finite element modeling of effect on the cutting forces of rake angle and approach angle in milling." Proceedings of the Institution of Mechanical Engineers, Part E: Journal of Process Mechanical Engineering. 2015. https://doi.org/10.1177/0954408915576698

[34] Shih, A. J. "Finite element analysis of the rake angle effects in orthogonal cutting." International Journal of Mechanical Sciences. 38(1), pp. 1-17. 1995. https://doi.org/10.1016/0020-7403(95)00036-W

[35] Gok, K. "Development of three-dimensional finite element model to calculate the turning processing parameters in turning operations." Measurement. 75, pp. 57-68. 2015.

https://doi.org/10.1016/j.measurement.2015.07.034 